\title{
Research on the Choice of Chinese Forest Products Channel Model: Commitment Perspectives
}

\author{
Haibo Zhu, Guijun Zheng \\ Business School of Center South of Forest and Technology University, Changsha, China \\ Email: qnlkw@126.com
}

Received 25 December 2015; accepted 22 January 2016; published 25 January 2016

Copyright (C) 2016 by authors and Scientific Research Publishing Inc.

This work is licensed under the Creative Commons Attribution International License (CC BY). http://creativecommons.org/licenses/by/4.0/

c) (i) Open Access

\begin{abstract}
In researching channel relation it can be found that different negotiating abilities (channel power) decide commitment levels and different commitment levels decide the choice of channel model if we research the channel model choice of forest products in the perspective of channel members' commitments. So leading enterprises, forest growers and distributors need to decide their commitment level according to their own negotiating ability in the channel system, and then choose right channel model.
\end{abstract}

\section{Keywords}

Forest Product Channel, Commitment, Negotiating Ability, Channel Model

\section{Introduction}

As the competition is becoming more and more serious, channel has become the important means for enterprise to gain competitive advantages, but which channel's model to apply, channel's efficiency, and economic benefits stir controversy among enterprises. In Chinese enterprises' practices there are kinds of channel models, some of which focus on short-term trading and the other some work for long-term relationships. Different channel models show different goals and behaviors. Most researches on channel models start in circulation and trade cost. This perspective is chosen by most scholars who assume to build circulation system of forest products based on analyzing transaction cost and expenses. Recent years, the number of scholars who research the forest channel in the perspective of relation in sociology is becoming larger as relation is concerned widely as a culture that is praised highly by Chinese in recent years. This paper tries to research the channel model choice of forest products in the perspective of channel members' commitments. 


\section{Reviewing Important Literatures and Basic Points}

Commitments belong to the concept of relational channel and the channel relation means contact state, cooperation, companion and alliance among each member with business in a common channel. The development process is: transaction-cooperation-partnership-alliance. We call the three latter as relational channel relation and the first transactional channel relation.

Relational channel relation focuses on building and developing cooperation among channel members and takes solving these relations correctly as the core of the channel. It aims at improving the quality and efficiency of the channel, starts from the point of cooperation, two-to-win and communication and emphasizes the control of marketing channel. Usually marketers play the role of a relational manager: build, coordinate and maintenance the relation with dealers. This kind of channel is characteristic of coordination, two-way information communication and marketing reciprocity.

After analyzing literatures it is found that research on relational channel mainly concentrate on the following four factors.

\subsection{Competitive Advantages of Relational Channel}

To build a relational channel could bring its members competitive advantages [1], satisfy customers’ needs better and improve profits. For example, retailers in a relational channel could take competitive advantages in supply, product popularization and promotion allowance, suppliers could take the advantage in getting market information and special product popularization. In a word, the relational channel could enhance the performance [2] [3].

\subsection{The Management of a Relational Channel}

In view of the importance of channel relation scholars start to study how to maximize its performance by the effective management of channel relation. From the perspective of sociology, economic and organizational behavior they quoted some conception and theories and advanced many theories on channel relation [4]. For example, quoted the research findings from study fruits of economics the resource-depend theory mainly research the channel power and its structure with the opinion that channel relation could be divided into different level to manage and guide by analyzing power origination. This theory gives some bases to people for explaining relational behavior among the channel. The relational commitment theory tarts from the sociological and organizational perspectives to research the factors as the channel members' trust, commitments and satisfaction and focus seriously on the contents of keeping and coordinating relation.

\subsection{The Influence Dimensions of Relational Channel}

On this point there are a branch formed the centre of trust and satisfaction and the other with the centre of trust and commitment [5]. Kim [6] thought commitment was the core variable needed to consider in building channel relation, which meant the leak-tightness of commercial joints between an enterprise and channel members. Morgan and Hunt [7] researched and thought that continuous transactional relation is remarkable for trust, commitment and satisfaction. Jan B. Heide [8], Barton A. Weirz and Sandy D. Jap [3] thought that the key variables of trust and commitment were the important factors for the influence of channel relation, that the essence of commitment is stabilization and abandon, that commitment meant a long-term relation guidance and rather realizing mutual long-term development even with the loss of the short-term profits for both [9]. Morgan and Hunt [7] advanced that such factors as mutual value, relational profits expectation, communication, the cost of relation cease and opportunism are the decision ones of building the instruction of the relation between trust and commitment. Bowen and Shoemaker (1998) divided specifically the factors affected trust and commitment and they thought commitment depended on reasonable cost, transfer cost, profits and mutual values, trust depended on speculative behavior, communication, reputation, former experiences enterprises' characteristic and mutual value, and then both trust and commitment decide relational members behaviors: extra consumption, retreatment and voluntary cooperation.

All headings should be in bold face. First-level headings should be numbered using I, II, III etc with cap for the first letter of each word. Second-level subheadings should be set flush left with initial caps and not numbering. Please do not use headings other than these two types. At least one-line space should separate these head- 
ings from the preceding text.

\subsection{Channel Patterns and Models}

Now study on channel patterns and models mainly consist of two branches: relation quality model by Crosby, Evans and Cowles [10] that channel relation quality decides the performance of a channel and key middle valuable model namely KMV by Morgan and Hunt [7] that relational commitment and trust were the core of building and maintaining channel relation and they were also basic factors of high channel performance.

In a study on insurance industry from the perspective of interpersonal relation Crosby, Evans and Cowles [10] built Relational Quality Model to explain the relation formed between salesmen and customers. Its fruits show that the characteristics (appearance, life style and social economical status) and relational quality are relative to sales results and that the more similar the personality of salesmen is to customers', the more beneficial it is to build and maintain relation, then to improve selling. So trust and satisfaction is believed the composition of relational quality and to determine sales fruits and the future relation.

Taking motor-tire industry as research subject Morgan and Hunt [7] advanced KMV model applying to the relation between enterprises in order to build a complete structure of channel relation. As a channel had been with both trust and commitment its efficiency would be improved. Namely a relation with good quality was built directly for trust and commitment and the good quality would cause successful marketing. KMV model greatly influenced the study on channel relation model, after them there were lots of scholars who deepened and extended KMV model. IK Whan G. [11] Based on further study on relations in supply chains and by using transaction cost theory and social transaction theory Kwon and Taewon Suh [11] advanced Trust and Commitment Model in supply chain relationship with the main point of influence of transaction uncertainty to relation. Bowen and Shoemak (1998) advanced a customer-centered relation model of service industry MRS model on the base of KMV. From the above it is obvious that study on channel relation has been deepening and with lots of fruits. But existing theories are not perfect. Though trust and commitment are key factors of the management of channel relation the former study wasn't refer to the relationship between commitment level and the choice of channel model (Zhao Xiaofei, 2009). So this paper is concerned on what relation between the choice of channel model of forest products and commitment level.

\section{Analysis on Commitment in Channel Relation}

Channel commitment reflects close-knit degree among channel members and it is each member's expectancy and behavior to maintain their own value relation. Dwyer, Schurr, and Oh [12] thought that commitment was important guarantee to maintain channel relation and important factor to gain long-term channel relation because commitment meant mutual willing to gain long-term profits at the cost of giving up short-term profits. Garbarino, E.\& M. S. Johnson. [13] thought commitment was conspicuously influential to the future intentions in relational channel.

Channel members all expect their value relation with continuity. This paper supposes that the value of channel relation causes both sides of value relation expect for continuity and both sides are willing to specifically invest relation and it will cause an effect Lock-up and tighten channel relation. Dwyer Schurr and Oh [12] thought rising switch cost would promote channel members to strive for improving the quality of channel relation. Anderson and Weitz [3] thought commitment was members' willing to assets investment and an investment behaviors which could be depended in the future. Because of switch cost, assets investment is hard to transfer into other channel. Morgan and Hunt [7] thought switch cost would occur if terminating a channel relation. Therefore, channel members are declined to maintain long-term channel relation for reducing or avoiding switch cost.

Bargaining power is an important variable in determining commitment level in channel inner system. Generally, bargaining power will be reflected through self scale, brand influence, market status and the creation of economical value. The larger self scale, the higher market status and the greater economical value creation, the stranger bargaining power. But there is an inverse ratio between commitment level and bargaining power. A and $B$ are supposed to be each member of both sides and it shows that if A's commitment level is higher than B's, A's bargaining power is weaker than B's, namely A's channel power is weaker than B's and reversely the result will also be on the contrary.

According to this idea we can build a choice frame of channel model based on commitment level as following Figure 1. 


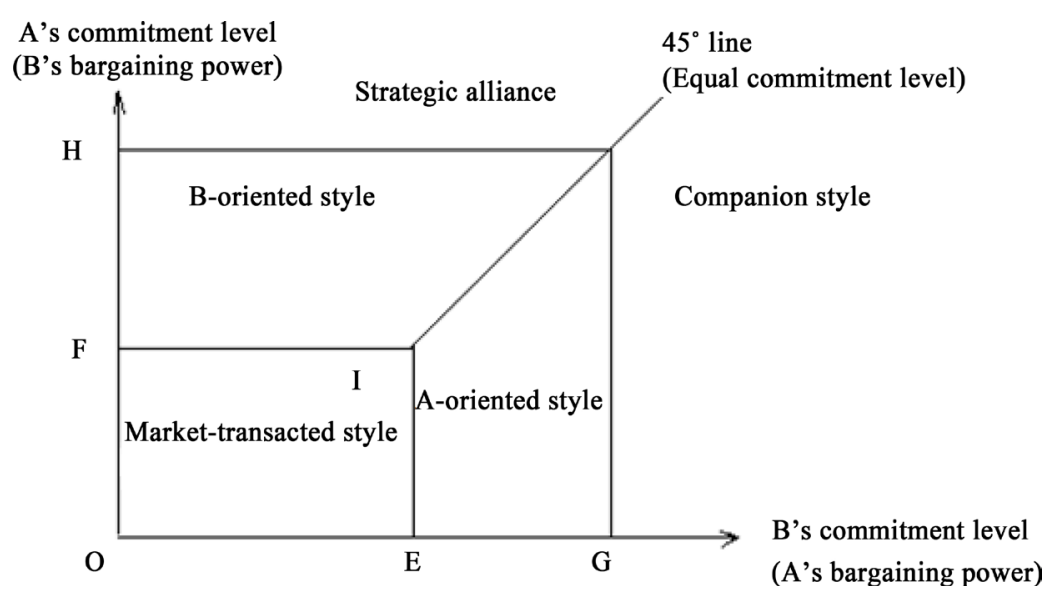

Figure 1. Analysis frame of matching between commitment and channel model.

In the area OFIE, for both sides' low commitment level(weak bargaining in channel cooperation), the best choice of channel model is market-transacted style; $45^{\circ}$ line mean the equality of both sides' commitment; in the area FIKH above line IK the channel model should be B-oriented style for A's higher commitment level; in the area IEGK under IK the channel model should be A-oriented style for B's higher commitment level; in the area above HK and on the right of KG strategic alliance or companion relation should become the best choice of channel model for the reason that both sides' commitment level is as high as a specific value (HK and GK stand for high commitment level), namely both sides' bargaining power is strong and they depend on each other.

\section{The Channel Model of Forest Products Matched with Commitment Level}

The members of marketing channel of forest products mainly consist of forest growers, leading enterprises and distributors. This paper will specifically use the scale of forest growers, the market power of leading enterprises and contributors' value-added ability to measure these three members' bargaining power. They are separately divided as normal forest growers and great forest growers, well-known leading enterprises and normal leading enterprises, normal distributors and large chain retailers.

According to the third part of this paper, the smaller forest growers, the lower leading enterprises commitment level; the greater leading enterprises' market power, the higher forest growers' commitment level. When a contributor can make great added value leading enterprises will attach importance to the coordination and cooperation with this contributor; but if added value is small leading enterprises will pay no attention to the contributor or even the relation quality with it.

If choosing the two sides with direct relation as the study objective on the marketing channel model of forest products, the patterns are as the following:

- forest growers-distributors;

- forest growers-leading enterprises;

- distributors-leading enterprises.

This paper will not discuss the first pattern, In this case, the whole value chain is too small and there are only forest growers and distributors as the channel members.

\subsection{Forest Growers—Leading Enterprises}

The channel model for leading enterprises with low market power and normal forest growers is market-transacted style. Small scale of forest growers and low market power of leading enterprises cause their low commitment and the lack of channel impulse to build a close coordination and cooperation. That is why market transaction is a main channel model to solve the problem of sale and circulation of forest products.

The channel model for leading enterprises with low market power and great forest growers is forest growers-oriented style. As growers in the channel have great scale, large production capacity and excellent reputation they can bring added-value to the leading enterprises and with low market power the leading enterprises can't maintain close collaboration with great growers for a rich supply until commit much enough. 
The channel model for the leading enterprises with great market power and normal growers is leading enterprises-oriented style. The leading enterprises are hardly substituted for great market power and are affected little for normal growers' low added-value. So leading enterprises commit little and instead, normal growers have to submit their channel power for share their market advantage. The result is that growers always commit too much and depend on leading enterprises.

The channel model for leading enterprises with great market power and great forest growers with large scale is companion style. In this case, powerful alliance can keep continual competitive advantage and extra-profits. Both would cherish the relation with the other and both their commitment level is high and relative low risk brought by the scale comparison advances a foundation for long-term companion (Figure 2).

The following Figure 3 is on the channel model of forest products for main channel members "leading enterprises-distributors".

\subsection{Distributors-Leading Enterprises}

The channel model for leading enterprises with low market power and normal distributors is market-transacted style. Both sides' commitment level will be low that building a short-term channel relation is more profitable.

The channel model for leading enterprises with low market power and great chain retailers is distributorsoriented style. Great chain retailers are efficient and professional sale terminals because of the large scale, considerable capital and chain management crossing region. Relying on the strong sales network it is simple for them to strive for sale and what they need to do is to deal with the relation with chain retailers. So great chain retailers usually act as the leader of a channel who control the channel and consider how to add the value of
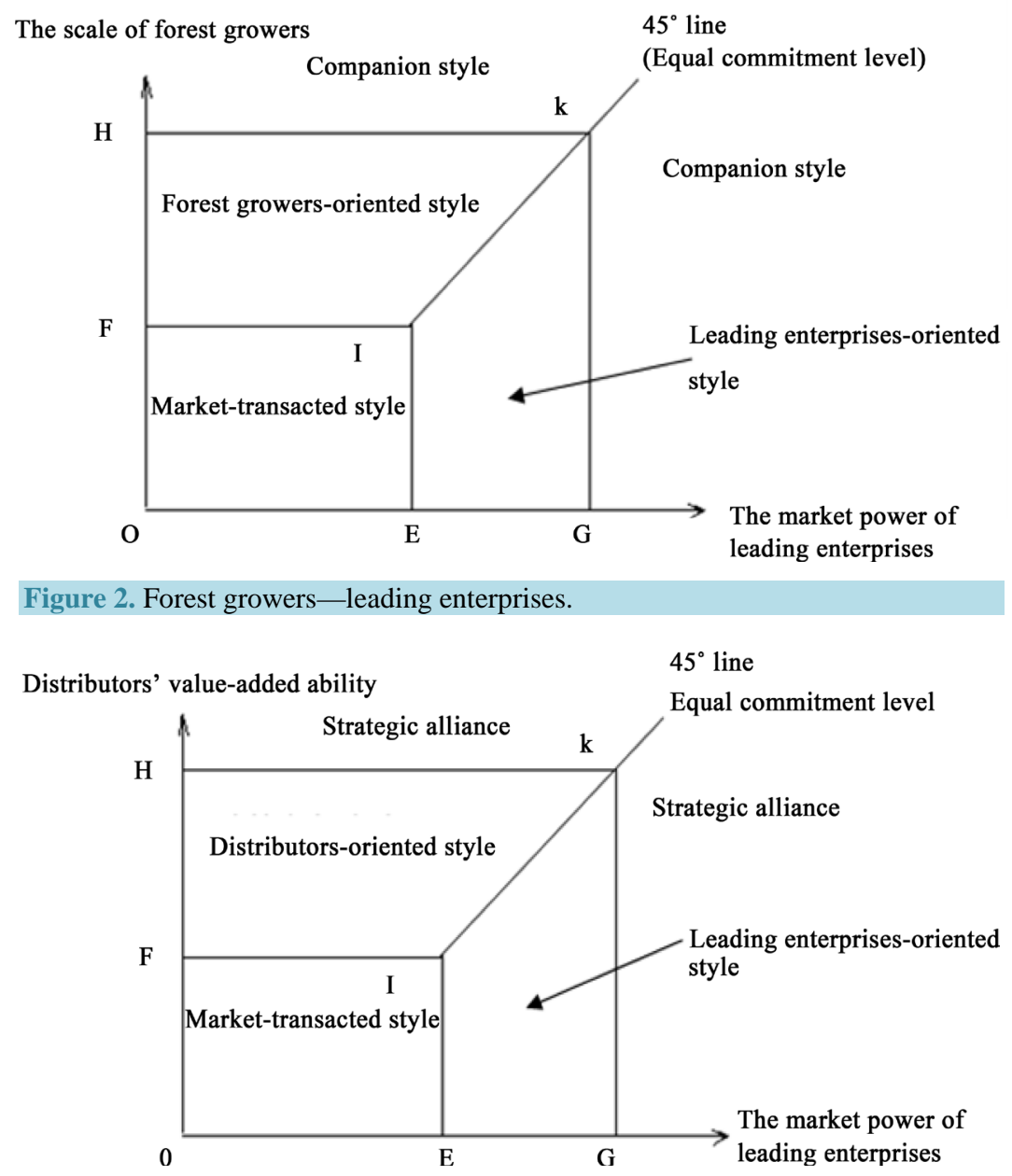

Figure 3. Distributors-leading enterprises. 
whole industrial chain and seek for a leading enterprise who can supply products at ideal price. But the leading enterprises have to choose to follow great distributors closely and build a stable relation positively.

The channel for the leading enterprises with great market power and normal retailers is leading enterprises-oriented style. If a leading enterprise has great market power it will become compelling among distributors and become their leader in the channel. Normal distributors can't create added value who are more concerned about what manufacturers desire or expect for them and need rely on leading enterprises' brand and follow the marketing strategic action.

The channel for leading enterprises with high market power and great chain retailers is strategic alliance. The great market power of leading enterprises and the great value-added ability of great chain retailers make both sides feel it necessary to cooperate with each other and their commitment reach a high level, so the relation really turn from market transacted-style to relational one with the guide of strategic alliance. And channel members will treat the relation with the other from the team perspective and control marketing channel based on collaboration, win-win and communication. Then both sides not only have strong willing to keep close relation but also can give up their own temporary profits to promote the coordinative development of the whole channel system.

\section{Conclusions}

In recent years strategic alliance is a heat word in management papers. Building cooperative companion channel and the strategic alliance is the important way to realize channel goal. It appears well as continual and collaborative relation and the internal potential of channel alliance can be proved by the example of collaborative commercial channel model of Wal-Mart and P\&G.

Companion marketing is necessary for the relative development of marketing. But building this kind of channel model is not simply to sign an agreement; its building and maintenance require certain base, some methods and conditions. These bases and premises are mainly mutual future goal, trust and to enjoy mutual profits.

We should choose cooperative companion with mutual prospect among existing trade object and build a mechanism of information sharing. For example, technology support and mechanism of information sharing can be added into the agreement and distributors must promise to feed back market demands to leading enterprises. A lot of practices demonstrate that these supports greatly improve forest growers' management efficiency and thereby improve the efficiency of the whole channel system. Finally each cooperative side will benefit from it.

Mutual trust will produce a positive effect. So a trust system must be built between growers and leading enterprises. Based on mutual trust it is possible for all three sides to pursue mutual super goal and then for relation stability and long-term success each side is willing to reach a compromise to improve the efficiency and the performance of the channel.

Inner-desire of maintaining companion channel is long-term cooperation which bases firstly on mutual trust. The original foundation of building cooperation is mutual profits which will attract both sides more as they become higher. Finally, sharing profits and loss and the match of responsibility and profits really contribute to the long-term exist of mutual cooperation.

\section{Acknowledgements}

This article is supported by the funding of Hunan Province Training key young teachers (project numbers: 2008zhb0005), allow us to thank them for the kindness.

\section{References}

[1] Ganesan, S. (1994) Determinants of Long-Term Orientation in Buyer-Seller Relationship. Journal of Marketing, 5, 32-35. http://dx.doi.org/10.2307/1252265

[2] Noordeewier, T.G., George, J. and Nevin, J.R. (1990) Performance Outcomes of Purchasing Arrangement in Industrial Buyer-Vendo Relationship. Journal of Marketing, 6, 56-58.

[3] Anderson, E. and Weitz, B. (1992) The Use of Pledges to Build and Sustain Commitment in Distribution Channels. Journal of Marketing Research, 29, 21-26. http://dx.doi.org/10.2307/3172490

[4] Wang, Z.H., Ni, X.J., Li, H.Z. and Wang, Y. (2003) Study on Relational Commitment Value of Channel Members. Commercial Research, 9, 63-65.

[5] Yang, J. (2007) Study on Channel Relation Model of Mobile Phone Based on Trust and Commitment. Zhejiang Industrial and Commercial University, Zhejiang. 
[6] Kim, K. and Frazier, G.L. (1996) A Typology of Distribution Channel Systems: A Contextual Approach. International Marketing Review, No. 1.

[7] Morgan, R.M. and Hunt, S.D. (1994) The Commitment-Trust Theory of Relationship Marketing. Journal of Marketing, 7, 18-23. http://dx.doi.org/10.2307/1252308

[8] Heide, J.B. and John, G. (1988) The Role of Dependence Balancing in Safeguarding Transaction-Specific Assets in Conventional Channels. Journal of Marketing, No. 1.

[9] Zhang, J.Y. (2005) Relational Channel: A Channel Structure Appearing Day by Day. Financial Economy, No. 10.

[10] Crosby, L.A., Evans, K.R. and Cowles, D. (1990) Relationship Quality in Service Selling: An Interpersonal Influence Perspective. Journal of Marketing, No. 3.

[11] Kwon, I.W.G. and Suh, T. (2004) Factors Affecting the Level of Trust and Commitment in Supply Chain Relationship. The Journal of Supply Chain Management, No. 7.

[12] Dwyer, F.R. (1982) Channel-Member Satisfaction: Laboratory Insights. Journal of Retailing, 11, 45-65.

[13] Garbarino, E. and Johnson, M.S. (1999) The Difference Roles of Satisfaction, Trust and Commitment in Customer Relationships. Journal of Marketing, 2, 55-59. 